\begin{tabular}{|c|l|}
\hline Title & In situ observation of damage structure in ODS austenitic steel during electron irradiation \\
\hline Author(s) & Oka, H.; Watanabe, M.; Kinoshita, H.; Shibayama, T.; Hashimoto, N.; Ohnuki, S.; Y amashita, S.; Ohtsuka, S. \\
\hline Citation & $\begin{array}{l}\text { Journal of Nuclear Materials, 417(1-3), 279-282 } \\
\text { https://doi.org/10.1016/.jnucmat.2010.12.156 }\end{array}$ \\
\hline Issue Date & 2011-10-01 \\
\hline Doc URL & http://hdl.handle.net/2115/47975 \\
\hline Type & article(author version) \\
\hline File Information & JNM417-1-3_279-282.pdf \\
\hline
\end{tabular}

Instructions for use 


\section{In-situ Observation of Damage Structure in ODS Austenitic Steel during Electron Irradiation}

Hiroshi Oka ${ }^{1, *}$, M. Watanabe ${ }^{2}$, H. Kinoshita ${ }^{1}$, T. Shibayama ${ }^{1}$, N. Hashimoto ${ }^{1}$, S. Ohnuki ${ }^{1}$, S. Yamashita $^{3}$, S. Ohtsuka ${ }^{3}$

${ }^{1}$ Faculty of Engineering, Hokkaido University, N-13, W-8, Kita-ku, Sapporo 060-8628, Japan

${ }^{2}$ Institute for Materials Research, Tohoku University, 2-1-1 Katahira, Aoba-ku, Sendai 980-8577, Japan

${ }^{3} \mathrm{O}$-arai Research and Development Center, JAEA, O-arai, Ibaraki 311-1393, Japan

[Corresponding Author]

Name : Hiroshi Oka

Postal address : Faculty of Engineering, Hokkaido University, N-13, W-8, Kita-ku, Sapporo 060-8628, Japan

Telephone number : 81-11-706-6769

Fax number :

E-mail address : hiroshi_oka@eng.hokudai.ac.jp 


\title{
In-situ Observation of Damage Structure in ODS Austenitic Steel during Electron Irradiation
}

\author{
Hiroshi Oka ${ }^{1, *}$, M. Watanabe ${ }^{2}$, H. Kinoshita ${ }^{1}$, T. Shibayama ${ }^{1}$, N. Hashimoto ${ }^{1}$, S. Ohnuki $^{1}$, \\ S. Yamashita ${ }^{3}$, S. Ohtsuka ${ }^{3}$
}

\author{
${ }^{1}$ Faculty of Engineering, Hokkaido University, N-13, W-8, Kita-ku, Sapporo 060-8628, Japan \\ ${ }^{2}$ Institute for Materials Research, Tohoku University, 2-1-1 Katahira, Aoba-ku, Sendai 980- \\ 8577, Japan \\ ${ }^{3}$ O-arai Research and Development Center, JAEA, O-arai, Ibaraki 311-1393, Japan
}

\begin{abstract}
The oxide dispersion strengthening method was applied to an austenitic stainless steel based on SUS316 by mechanical alloying with additions of minor alloying elements. This ODS austenitic stainless steel was electron-irradiated to investigate the damage structure. Microstructural observation revealed that ODS austenitic stainless steel has a fine distribution of complex oxides. The in-situ observation during electron irradiation showed that both dislocation loops and small cavities nucleated at the interface between oxide particles and matrix. In the case of helium implantation, defect clusters also nucleated at the interface. These results suggest that the oxide interface is an effective sink for irradiation-induced point defects and helium atoms.
\end{abstract}

Keywords:

ODS, austenitic stainless steel, mechanical alloying, electron irradiation, helium implantation 


\section{Introduction}

The oxide dispersion strengthened (ODS) ferritic steels are candidates for structural materials of fusion reactors and core components of advanced fission reactors, because of excellent high-temperature strength, creep rupture life and irradiation resistance [1-4]. However, ferritic steels have poor corrosion resistance compared to austenitic steels in general. For developing structural materials of fusion reactors and core components of advanced fission reactors, ODS austenitic stainless steels could be an attractive materials because of their corrosion resistance, high temperature strength and irradiation properties.

Another important issue for fusion reactor materials is the gaseous transmutation effect on defect cluster formation. The (n, $\alpha)$ nuclear reaction caused by $14 \mathrm{MeV}$ fast neutrons produces helium atoms, which precipitate as bubbles and enhance void swelling [5]. Void swelling is known to influence the dimensional stability of irradiated materials. Recent work suggested that the oxide particles in the ODS steel were effective trapping site for helium and vacancies, so that the oxide particles have an influence on the nucleation and growth of cavities [6]. In this research, we have successfully developed an ODS austenitic stainless steel containing nano-sized oxide particles introduced by means of mechanical alloying (MA). Electron irradiation and nano-characterization were carried out to clarify the effect of oxide particles on defect cluster formation and helium precipitation.

\section{Experimental}

An advanced austenitic stainless steel, PNC316, was provided by JAEA [7], and the chemical composition is shown in Table 1. The ODS austenitic stainless steel (ODS-316) was fabricated by the MA process from argon gas-atomized PNC316 powder of $\sim 150 \mu \mathrm{m}$ diameter and $0.35 \mathrm{wt} \% \mathrm{Y}_{2} \mathrm{O}_{3}$ powder. The minor alloying elements, $0.1 \mathrm{wt} \% \mathrm{Ti}$ and $0.6 \mathrm{wt} \% \mathrm{Hf}$, were added to obtain a fine dispersion of oxide particles. These powders were alloyed mechanically in a planetary ball mill (Fritsch $\mathrm{GmbH}$ ) in an argon gas atmosphere. MA was performed for $48 \mathrm{~h}$ with a rotation speed of $440 \mathrm{rpm}$ and ball-to-powder ratio of 5.5:1. After MA, the particles were heat treated for $2 \mathrm{~h}$ at $1423 \mathrm{~K}$ in a vacuum, and then water quenched. For comparison, PNC316 samples were also heat treated with the same conditions.

Samples for electron irradiation and in-site observation were prepared by mechanically polishing followed by electrochemical-polishing. Multi-energy (30, 70 and $100 \mathrm{keV})$ helium ions were injected in 
some specimens in order to implant uniformly in depth, to an average concentration of 100 appm. Figure 1 shows the estimated depth profile of the helium calculated by TRIM code.

In-situ observation during electron irradiation was carried out using a high voltage electron microscopy (HVEM) operated at $1250 \mathrm{kV}$, at temperatures of 723 and $823 \mathrm{~K}$. The dose rate and maximum dose were $3.4 \sim 4.2 \times 10^{-3} \mathrm{dpa} / \mathrm{sec}$ and $15 \mathrm{dpa}$.

\section{Results and discussion}

The microstructure of PNC316 before irradiation was a typical annealed structure with a very low density of dislocations. The microstructure of ODS-316 before irradiation included a fine dispersion of oxide particles with a low initial dislocation density. The number density and mean size of the dispersed particles were about $3.17 \times 10^{22} \mathrm{~m}^{-3}$ and $8.8 \mathrm{~nm}$, respectively.

Electron irradiation was carried out in areas with uniform oxide distributions. Figure 2 shows microstructural changes of ODS-316 during electron irradiation at $723 \mathrm{~K}$. It was observed that dislocation loops nucleated and grew at the interface between oxide particles and matrix, indicated by an arrow. Point defect concentrations induced by electron irradiation normally lead to formation of dislocation loops. The observed nucleation of dislocation loops at the oxide/matrix interface due to the condensation of point defects above the critical concentration can be explained as a result of the sink effect of the oxide/matrix interface. The high mobility of interstitial atoms compared to that of vacancies at this temperature could enhance the formation of dislocation loops.

Figure 3 shows the comparison of cavity evolutions in PNC316 and ODS-316 irradiated at $823 \mathrm{~K}$. Large faceted cavities were introduced in PNC316 (Fig. 3(a)-(c)). For ODS-316, cavities nucleated at the interface as shown in Fig. 3(d)-(f). This result indicates that the oxide/matrix interface acts as a sink for vacancies. High concentration of vacancy in the matrix due to the initial growth of dislocation loops contributes to the nucleation of cavities at the interface. In addition, some cavities in ODS-316 (Fig. 3(d)(f)) seems to be rounded. Based on past experiences with ODS steel fabrication, these cavities are deduced to contain gas atoms such an argon picked up during fabrication [8]. Such gas atoms also contribute to the nucleation of cavities at the oxide/matrix interface.

Figure 4 shows the mean size and number density of cavities as a function of dose at $823 \mathrm{~K}$. The mean size and number density of cavity in ODS-316 were small and high compared to those in PNC316, 
respectively. ODS-316 showed good resistance to swelling which was estimated to be less than $0.2 \%$ up to about 15 dpa from the mean size and number density of cavities. This shows the fine dispersed oxide particles are obviously effective in suppression of cavity coarsening and contributes to limiting defect clusters to small size. Part of oxide particle seems to be incoherent with respect to the matrix from TEM observations. This gives a hint that the oxide/matrix interface is the neutral sink for point defects as well as grain boundaries.

To improve the effect of dispersed oxide particle in ODS-316 for suppression of cavity coarsening, the ideal distribution parameter of oxide particles should be considered as follows. In case the distance of oxide particle is longer than the mean free path of vacancy at irradiation temperature, only interstitial atoms can reach the interface by the sink effect. As a result, vacancy cluster is formed due to the condensation of vacancies above the critical concentration. The interface between oxide particle and matrix acts as a recombination site for point defects in the case that ODS-316 is designed to have an enough oxide particle separation compared to the mean free path of vacancies.

Electron irradiation experiments were also carried out on helium implanted specimens. Cavities formed in both helium implanted PNC316 and ODS-316. There was a clear influence of implanted helium on cavity formation in PNC316. In a PNC316 specimen with 100 appm helium, the cavity number density was one order of magnitude higher than in a specimen without helium. This means the nucleation sites for point defects increase when helium atom exists in the matrix. On the other hand, the cavity number density in ODS-316 with and without helium was similar. This indicates that the number of nucleation sites did not change due to the implantation of helium in ODS-316. Additionally, it is notable that nucleation of cavities in ODS-316 occurs on the edge of oxide particle as shown in fig. 5(a)-(c), the same as in the ODS-316 without helium. From recent studies, helium atoms and vacancies easily bind together to become $\mathrm{He}-\mathrm{V}$ complexes [9]. The oxide interface has the role of being a sink site for $\mathrm{He}-\mathrm{V}$ complex, as well as for vacancies. Consequently, the injected helium has little influence on the cavity nucleation in ODS-316.

\section{Summary}

In-situ observations during electron irradiation were carried out to investigate the effects of oxide particles in ODS austenitic stainless steel on defect cluster formation and helium precipitation. The nucleation of dislocation loops and cavities were observed on the interface of finely dispersed oxide 
particles in ODS-316. The mean size and the number density of cavities in ODS-316 were small and high compared to those in PNC316, respectively. It was also observed that small cavities formed around the oxide particle in ODS-316 containing 100 appm helium. This shows the oxide/matrix interface acts as a sink site for both point defects and helium atoms.

\section{Acknowledgement}

The authors would like to thank Mr. K. Sugawara and Mr. K. Ohkubo for technical support in electron irradiation experiments. 


\section{References}

[1] S. Ukai, M. Harada, H. Okada, M. Inoue, S. Nomura, S. Shikakura, K. Asabe, T. Nishida, M. Fujiwara, J. Nucl. Mater. 204 (1993) 65.

[2] S. Ukai, T. Nishida, H. Okada, T. Okuda, M. Fujiwara, K. Asabe, J. Nucl. Sci. Tech. 34 (1997) 256.

[3] M.B. Toloczko, D.S. Gelles, F.A. Garner, R.J. Kurtz, K. Abe, J. Nucl. Mater. 329-333 (2004) 352.

[4] I. Monnet, P. Dubuisson, Y. Serruys, M.O. Ruault, O. Kaitasov, B. Jouffrey, J. Nucl. Mater. 311-321 (2004) 335.

[5] Y. Hidaka, S. Ohnuki, H. Takahashi, S. Watanabe, J. Nucl. Mater. 212-215 (1994) 330.

[6] K. Yutani, H. Kishimoto, R. Kasada, A. Kimura, J. Nucl. Mater. 367-370 (2007) 423.

[7] I. Shibahara, S. Ukai, S. Onose, S. Shikakura, J. Nucl. Mater. 204 (1993) 131.

[8] M. Klimiankou, R. Lindau, A. Moslang, Micron 36 (2005) 1.

[9] L.K. Mansur and W.A. Coghlan, J. Nucl. Mater. 119 (1983) 1. 
Table 1 The chemical composition of PNC316 (wt\%)

\begin{tabular}{l||lllllllll}
\hline element & $\mathrm{Fe}$ & $\mathrm{Cr}$ & $\mathrm{Ni}$ & $\mathrm{Mo}$ & $\mathrm{Mn}$ & $\mathrm{Ti}$ & $\mathrm{Si}$ & $\mathrm{Nb}$ & $\mathrm{C}$ \\
\hline PNC316 & bal. & 16.16 & 13.66 & 2.33 & 1.82 & 0.08 & 0.75 & 0.08 & 0.05 \\
\hline
\end{tabular}

Corresponding Author: Hiroshi Oka,

Column width: one columns 
Figure captions

Fig. 1 Estimated depth profile of helium based on the calculations of TRIM with 30,70 and 100keV helium ions.

Fig. 2 Formation of dislocation loop around an oxide particle in ODS austenitic stainless steel (ODS-316) irradiated to (a) 0 , (b) 0.8 and (c) $1.3 \mathrm{dpa}$ at $723 \mathrm{~K}$.

Fig. 3 Cavity evolution in PNC316 and ODS-316 irradiated at $823 \mathrm{~K}$. The upper photos show the PNC316 irradiated to (a) 7.6, (b) 12.7 and (c) 15.3 dpa. The lower photos show the ODS-316 irradiated to (d) 3.3, (e) 7.9 and (f) 13.2 dpa.

Fig. 4 Dose dependence of mean size and number density of cavities in PNC316 and ODS-316 irradiated at $823 \mathrm{~K}$.

Fig. 5 Cavity evolution in ODS-316 with 100 appm He irradiated to (a) 5.1, (b) 8.9 and (c) 14.0 dpa at $823 \mathrm{~K}$ 
Fig. 1

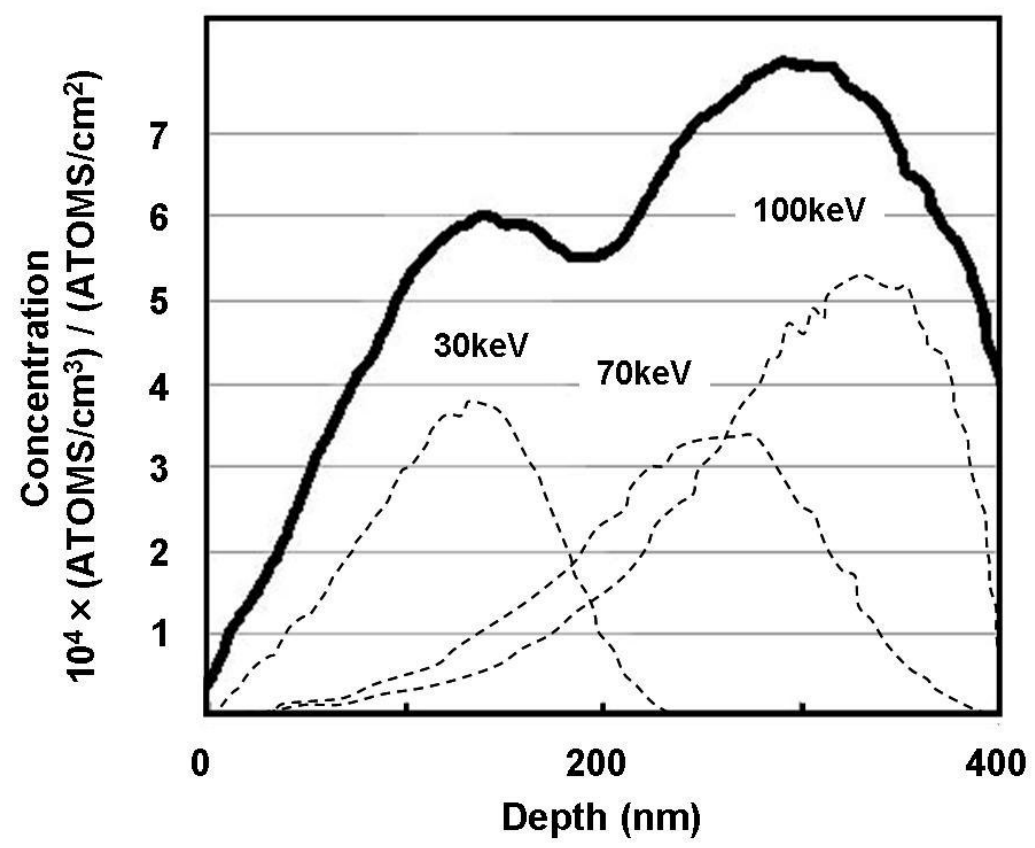

Fig. 1 Estimated depth profile of helium based on the calculations of TRIM with 30, 70 and 100keV helium ions.

Corresponding Author: Hiroshi Oka, Column width: one columns 
Fig. 2
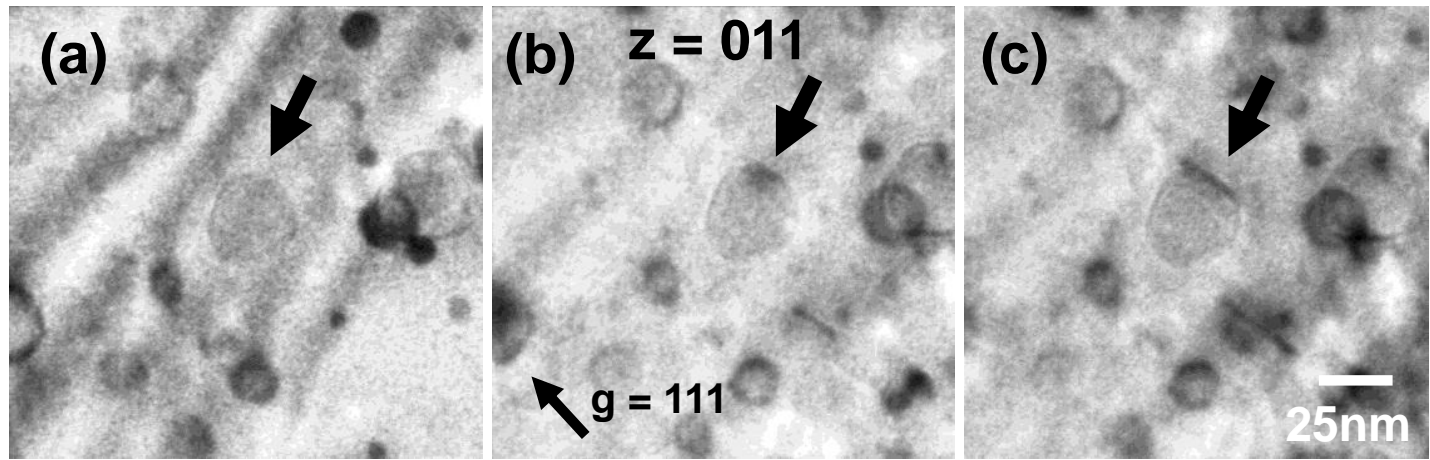

Fig. 2 Formation of dislocation loop around an oxide particle in ODS austenitic stainless steel (ODS316) irradiated to (a) 0 , (b) 0.8 and (c) $1.3 \mathrm{dpa}$ at $723 \mathrm{~K}$.

Corresponding Author: Hiroshi Oka,

Column width: two columns 
Fig. 3
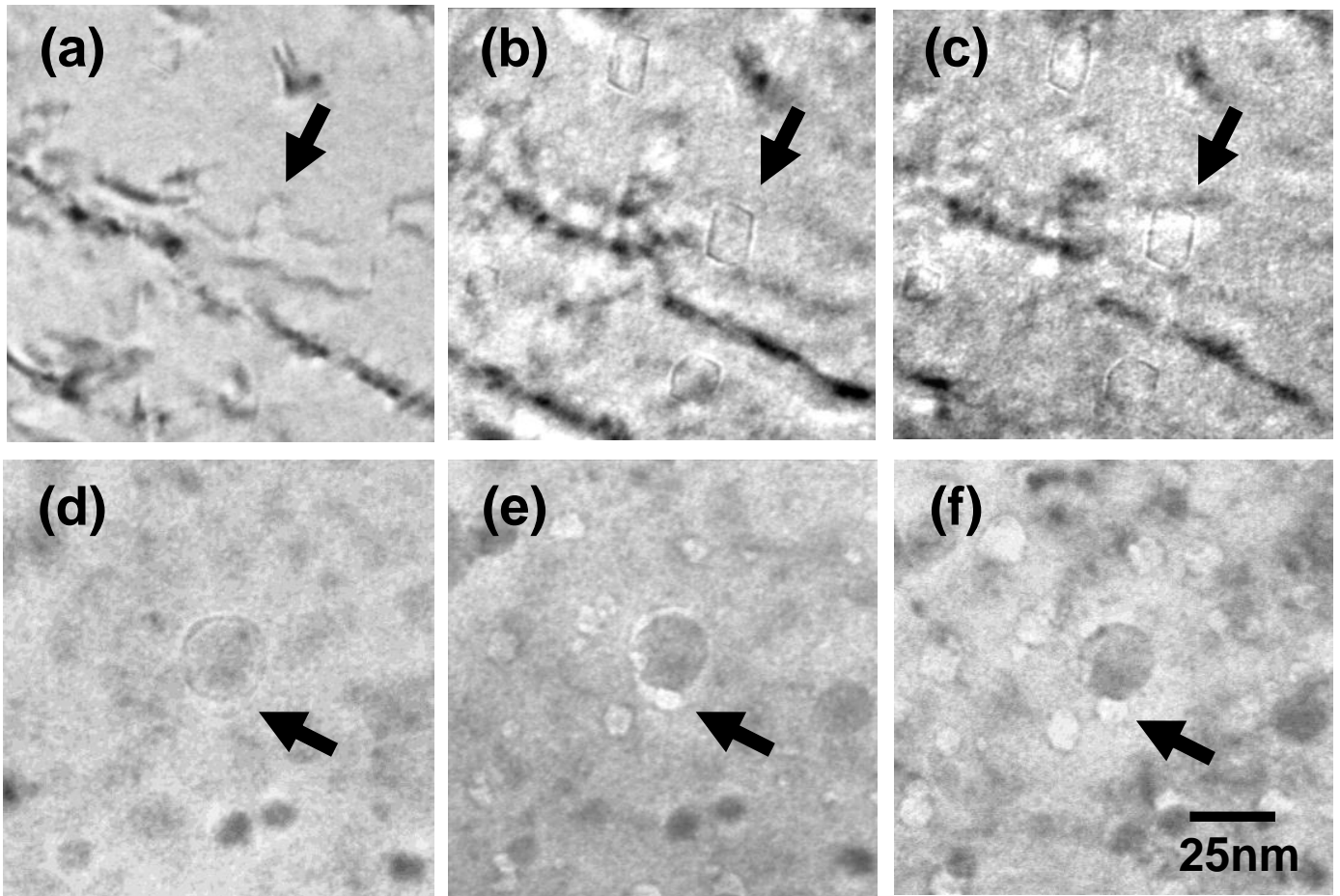

Fig. 3 Cavity evolution in PNC316 and ODS-316 irradiated at $823 \mathrm{~K}$. The upper photos show the PNC316 irradiated to (a) 7.6, (b) 12.7 and (c) $15.3 \mathrm{dpa}$. The lower photos show the ODS-316 irradiated to (d) 3.3 , (e) 7.9 and (f) 13.2 dpa.

\section{Corresponding Author: Hiroshi Oka,}

Column width: two columns 
Fig. 4
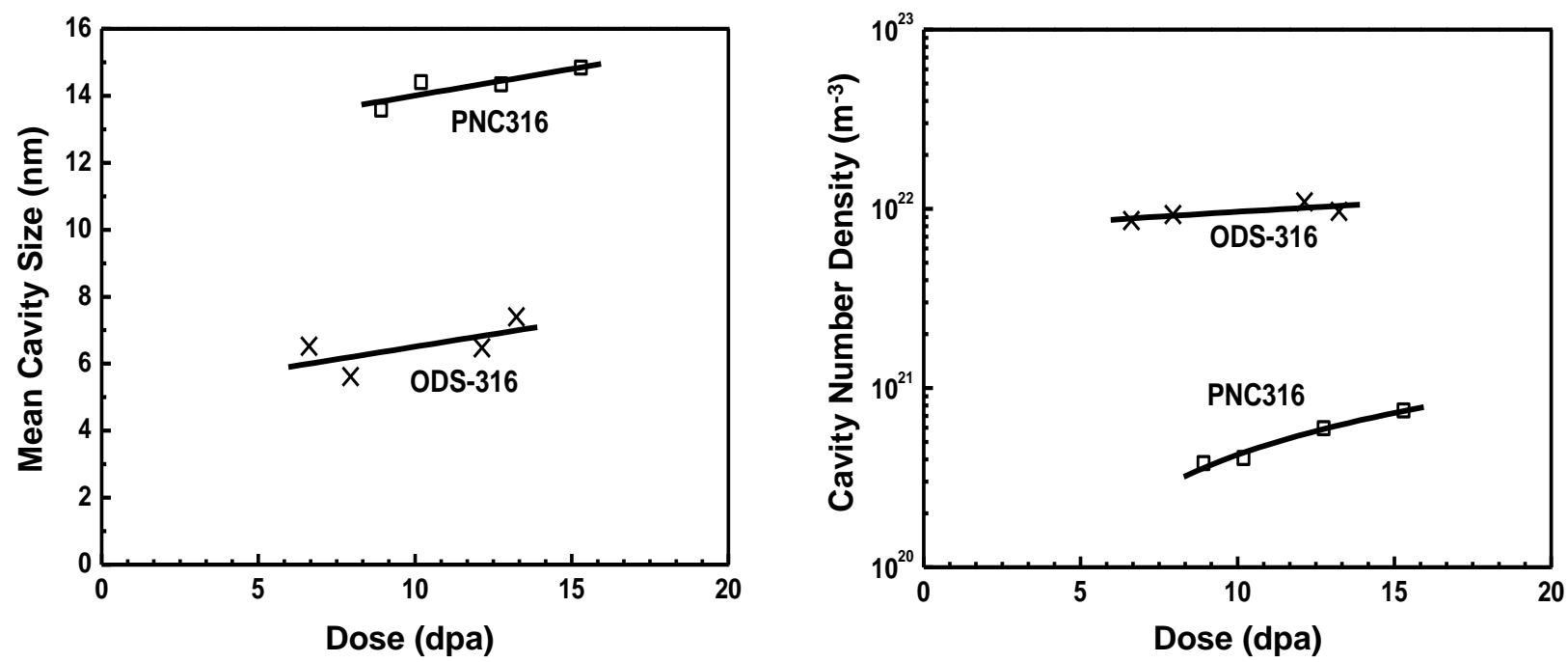

Fig. 4 Dose dependence of mean size and number density of cavities in PNC316 and ODS-316 irradiated at $823 \mathrm{~K}$.

Corresponding Author: Hiroshi Oka,

Column width: two columns 
Fig. 5
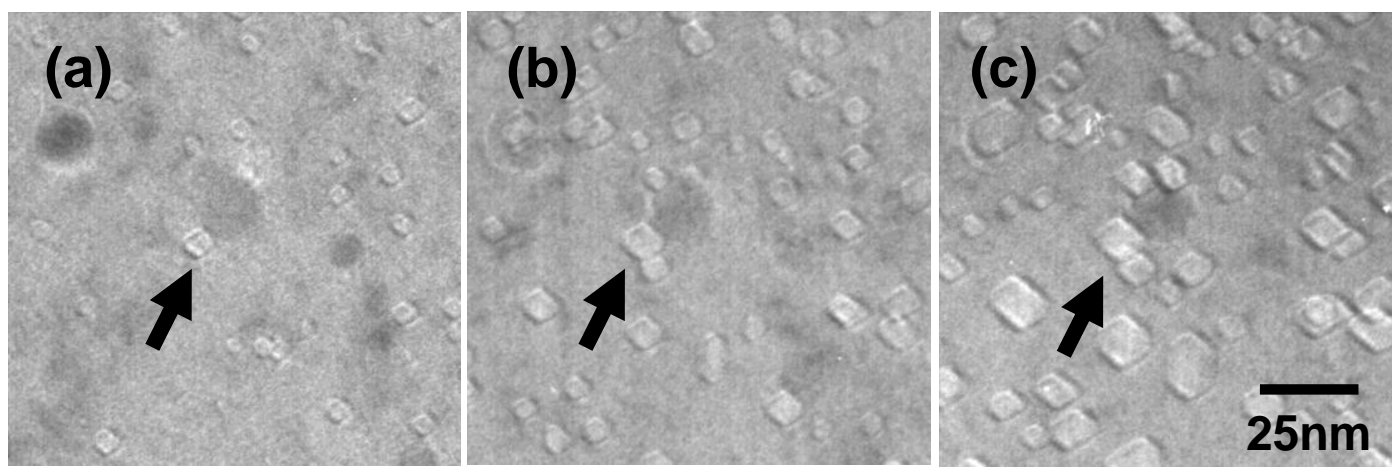

Fig. 5 Cavity evolution in ODS-316 with 100 appm He irradiated to (a) 5.1, (b) 8.9 and (c) 14.0 dpa at $823 \mathrm{~K}$.

Corresponding Author: Hiroshi Oka, Column width: two columns 